\title{
Deregulation of ocular nucleotide homeostasis in patients with
} diabetic retinopathy

\section{Loukovaara, Sirpa}

2017-02

Loukovaara , S, Sandholm , J , Aalto , K, Liukkonen , J , Jalkanen , S \& Yegutkin , G G 2017 , ' Deregulation of ocular nucleotide homeostasis in patients with diabetic retinopathy ' , Journal of Molecular Medicine , vol. 95 , no. 2 , pp. 193-204 . https://doi.org/10.1007/s00109-016-1472-6

http://hdl.handle.net/10138/232541

https://doi.org/10.1007/s00109-016-1472-6

publishedVersion

Downloaded from Helda, University of Helsinki institutional repository.

This is an electronic reprint of the original article.

This reprint may differ from the original in pagination and typographic detail.

Please cite the original version. 


\title{
Deregulation of ocular nucleotide homeostasis in patients with diabetic retinopathy
}

\author{
Sirpa Loukovaara ${ }^{1}$. Jouko Sandholm ${ }^{2} \cdot$ Kristiina Aalto $^{3}$ • Janne Liukkonen ${ }^{4}$. \\ Sirpa Jalkanen $^{3} \cdot$ Gennady G. Yegutkin ${ }^{3}$
}

Received: 11 July 2016/Revised: 31 August 2016 / Accepted: 7 September 2016 / Published online: 16 September 2016

(C) Springer-Verlag Berlin Heidelberg 2016

\begin{abstract}
Clear signaling roles for ATP and adenosine have been established in all tissues, including the eye. The magnitude of signaling responses is governed by networks of enzymes; however, little is known about the regulatory mechanisms of purinergic signaling in the eye. By employing thin-layer chromatographic assays with ${ }^{3} \mathrm{H}$-labeled substrates, this study aimed to evaluate the role of nucleotide homeostasis in the pathogenesis of vitreoretinal diseases in humans. We have identified soluble enzymes ecto-5'-nucleotidase/CD73, adenylate kinase-1, and nucleoside diphosphate kinase in the vitreous fluid that control active cycling between proinflammatory ATP and anti-inflammatory adenosine. Strikingly, patients with proliferative form of diabetic retinopathy (DR) had higher adenylate kinase activity and ATP concentration, when compared to non-proliferative DR eyes and non-diabetic controls operated for rhegmatogenous retinal
\end{abstract}

Electronic supplementary material The online version of this article (doi:10.1007/s00109-016-1472-6) contains supplementary material, which is available to authorized users.

Gennady G. Yegutkin

gennady.yegutkin@utu.fi

1 Unit of Vitreoretinal Surgery, Department of Ophthalmology, Helsinki University Central Hospital and University of Helsinki, Helsinki, Finland

2 Cell Imaging Core, Turku Centre for Biotechnology, University of Turku and Åbo Akademi University, Turku, Finland

3 MediCity Research Laboratory and Department of Medical Microbiology and Immunology, University of Turku, Tykistökatu 6A, 20520 Turku, Finland

4 Department of Ophthalmology, Turku University Hospital, Turku, Finland detachment, macular hole, and pucker. The non-parametric correlation analysis revealed positive correlations between intravitreal adenylate kinase and concentrations of ATP, ADP, and other angiogenic (angiopoietins-1 and -2), profibrotic (transforming growth factor- $\beta 1$ ), and proteolytic (matrix metalloproteinase-9) factors but not erythropoietin and VEGF. Immunohistochemical staining of postmortem human retina additionally revealed selective expression of ecto-5'-nucleotidase/CD73 on the rod-and-cone-containing photoreceptor cells. Collectively, these findings provide novel insights into the regulatory mechanisms that influence purinergic signaling in diseased eye and open up new possibilities in the development of enzyme-targeted therapeutic approaches for prevention and treatment of DR.

\section{Key message}

- Ecto-5'-nucleotidase/CD73 and adenylate kinase-1 circulate in human vitreous fluid.

- Adenylate kinase activity is high in diabetic eyes with proliferative retinopathy.

- Diabetic eyes display higher intravitreal ATP/ADP ratio than non-diabetic controls.

- Soluble adenylate kinase maintains resynthesis of inflammatory ATP in diabetic eyes

Keywords Diabetic retinopathy - Vitreous fluid - ATP - ADP . Ecto-5'-nucleotidase/CD73 · Adenylate kinase-1

\section{Introduction}

Diabetic retinopathy (DR) is a leading cause of vision impairment and blindness among working age people in developed countries, characterized by neuronal and glial dysfunctions; cell death in retinal capillaries; vascular leakage; vessel 
occlusion; retinal fibrosis; and in the proliferative form, invasion of abnormal blood vessels from the retinal circulation, growth of newly formed vessels (neovascularization), and lymphangiogenesis [1-4]. Numerous factors, such as vascular endothelial growth factor (VEGF) and angiopoietins (Ang), neurotrophic mediators somatostatin and neurotrophins, erythropoietin (EPO), tumor necrosis factor- $\alpha$ (TNF- $\alpha$ ), transforming growth factor- $\beta 1$ (TGF $\beta 1$ ), and other cytokines and chemokines, have been shown to be implicated in the pathogenesis of DR [3-7]. Current treatments for DR include systemic treatments of the classic risk factors (i.e., hyperglycemia and hypertension), anti-oxidant, anti-inflammatory and laser therapies, intravitreal injections of anti-VEGF drugs or corticosteroids, pars plana vitrectomy, and stem cell therapies for repairing the injured retinal microvessels [3-5]. Further development of preventional and interventional strategies against DR requires better understanding of the exact mechanisms underlying diabetes-induced microvascular, neurodegenerative, and inflammatory injuries.

ATP and other nucleotides and adenosine have emerged as important regulators of ocular functions, particularly involved in neuroprotection, intraocular pressure, immunomodulation, vasodilatation, and retinal functioning [8-12]. ATP and other purines are present in vitreous fluids (VFs) and aqueous humor, and their concentrations can be modulated in pathological conditions such as dry eye disease [13], glaucoma [10, 14, 15], ischemia reperfusion [8], age-related macular degeneration [16], and DR [17]. In diabetes mellitus, the basic cellular defects in metabolism and hyperglycemia may lead to altered intracellular and extracellular nucleotide levels, accompanied by changes in signaling pathways in the pancreas and selected tissues/organs, including eye [18].

Most models of purinergic signaling depend on interactions between distinct processes including (i) release of ATP and other purines, (ii) triggering of signaling events via a series of nucleotide- and nucleoside-selective receptors, and (iii) ectoenzymatic inactivation of purinergic agonists [19, 20]. General schemes of purine-converting pathways include nucleoside triphosphate diphosphohydrolase-1 (NTPDase1, also known as CD39), other enzymes of NTPDase and nucleotide pyrophosphatase/phosphodiesterase families, ecto-5'-nucleotidase/CD73 (eN/CD73), alkaline phosphatases, adenosine deaminase, and backward ATP-regenerating enzymes adenylate kinase (AK) and nucleoside diphosphate kinase (NDPK) $[19,21,22]$. Research over the past decade highlights the central role for CD39-CD73 axis in controlling the balance between ATP, ADP, and adenosine in a wide range of diseases, including endothelial barrier dysfunction and activation and aggregation of platelets at sites of vascular injury, hypoxia, and inflammation [20, 23, 24]. However, current knowledge of regulatory pathways governing the duration and magnitude of purinergic signaling in the eye remains rather scattered. Previous research has been focused on the expression of
NTPDases and/or $e$ N/CD73 in Müller glial cells of rodent retina and their role in neurovascular coupling [11, 25], osmotic cell swelling [26], and diabetes [12], as well as in rodent and primate retinas [15], human retinal pigment epithelial cells [27], and trabecular meshwork cells [28] in terms of the control of intraocular pressure and cytoskeletal remodeling.

By employing thin-layer chromatographic (TLC) enzymatic assays with ${ }^{3} \mathrm{H}$-labeled substrates, together with immunodepletion and histochemical approaches, this study aimed to evaluate the role of nucleotide homeostasis in the pathogenesis of vitreoretinal diseases in humans. The results obtained identify $e \mathrm{~N} / \mathrm{CD} 73$ and AK1 as key soluble enzymes in the human VF, and further suggest their contribution to the pathogenesis of DR, especially its sight-threatening form, proliferative diabetic retinopathy (PDR).

\section{Material and methods}

\section{Study design}

Vitreous specimens from 228 patients recruited in the Unit of Vitreoretinal Diseases (Helsinki University Central Hospital) were available for analysis. They were sub-grouped as follows: non-diabetic eyes operated owing to non-vascular vitreoretinal diseases, including rhegmatogenous retinal detachment (RRD), quiescent idiopathic macular hole $(\mathrm{MH})$ or pucker, as well as diabetic group comprising of PDR and nonPDR patients (Table 1). All vitrectomies were performed by a vitreoretinal surgeon, as described elsewhere [6, 7] (Fig. 1). The studies were conducted according to the principles of the Declaration of Helsinki and approved by the Institutional Review Board of the Helsinki University Central Hospital and the Ethical Committee. A signed informed consent was obtained from each participant. Additional information on sample collection and processing can be found in the Supplementary Material.

\section{TLC analysis of purine-converting activities}

ATPase, ADPase, eN/CD73, AK, NDPK, and adenosine deaminase were assayed by incubating the VF $(8 \mu \mathrm{l})$ with ${ }^{3} \mathrm{H}$ labeled and unlabeled ATP, ADP, AMP, and adenosine as appropriate substrates. ${ }^{3} \mathrm{H}$-labeled nucleotides and nucleosides were separated by TLC and then quantified by scintillation $\beta$-counting [29] or developed by autoradiography, as described in the Supplementary Material.

\section{Determination of intravitreal ATP, ADP, adenosine, and other biomarkers}

ATP, ADP, and adenosine were determined using enzymecoupled assays [17, 30]. For experimental details, see 
Table 1 Diabetes mellitus (DM), age and gender distribution, and purine concentrations among the patients studied

\begin{tabular}{llllll}
\hline Patients & \multicolumn{2}{l}{ Non-diabetic } & & \multicolumn{2}{l}{ Diabetic } \\
\cline { 2 - 3 } \cline { 5 - 6 } & RRD & MH/pucker & & PDR & Non-PDR \\
\hline Number & 112 & 31 & 40 & 46 \\
Males/females & $66 / 46$ & $7 / 24$ & $17 / 23$ & $28 / 18$ \\
DM1/DM2 & - & - & $23 / 17$ & $9 / 37$ \\
Age, years & $61.4 \pm 1.1$ & $68.7 \pm 1.1$ & & $46.0 \pm 3.0^{*}$ & $63.1 \pm 2.1$ \\
Duration of DM, years & - & - & $19.1 \pm 1.7$ & $15.0 \pm 1.8$ \\
Vitreous ATP, nM & $4.5 \pm 0.7$ & $3.1 \pm 0.9$ & & $86.0 \pm 33.1 * *$ & $26.1 \pm 14.8 * *$ \\
Vitreous ADP, nM & $21.2 \pm 3.3$ & $13.7 \pm 4.3$ & & $64.9 \pm 20.1$ & $23.1 \pm 7.0$ \\
Vitreous ATP/ADP ratio & $2.6 \pm 0.5$ & $1.6 \pm 0.9$ & & $9.0 \pm 6.4 *$ & $5.9 \pm 1.5 *$ \\
Vitreous adenosine, nM & $1226 \pm 106(91)$ & $1448 \pm 250(28)$ & $1323 \pm 377(20)$ & $1216 \pm 191(29)$ \\
Plasma ATP, nM & $1170 \pm 101(95)$ & $1389 \pm 281(31)$ & $1186 \pm 131(27)$ & $2100 \pm 514(30)$ \\
Plasma ADP, nM & $990 \pm 88(95)$ & $1122 \pm 187(31)$ & $988 \pm 127(27)$ & $1538 \pm 346(30)$ \\
Plasma Hb, mg/dL & $4.5 \pm 0.3(95)$ & $4.2 \pm 0.5(31)$ & & $4.4 \pm 0.3(27)$ & $4.4 \pm 0.5(30)$ \\
Blood HbA1c, \% & - & - & $9.2 \pm 0.5(20)$ & $8.4 \pm 0.3(20)$ \\
\hline
\end{tabular}

Vitreous ATP and ADP were assayed in all patients studied, while the levels of vitreous adenosine, plasma nucleotides, and hemoglobin $(H b)$, as well as glycated hemoglobin Alc $(H b A l c)$ in the whole blood were determined in the indicated patient number, as specified in the parentheses. Data are presented as mean \pm SEM $* P<0.05$ as compared with corresponding values from control RRD patients

$* * P<0.01$ as compared with corresponding values from control RRD patients
Supplementary Material. Matrix metalloproteinase-9 (MMP9) activity was assayed by gelatin zymography, while the concentrations of Ang-1, Ang-2, VEGF, EPO, and TGF $\beta 1$ were determined using Enzyme-Linked Immunosorbent Assay (ELISA) Kits, as described elsewhere [6].

\section{Immunohistochemical analysis of eN/CD73 expression in human retina}

Cadaver eyeballs were enucleated $36-48 \mathrm{~h}$ postmortem from two female donors without apparent eye diseases. The use of postmortem human tissues has been approved by the Ethical Committee of Turku University Hospital. Paraffin sections of the retina were stained with rabbit $\alpha$-CD73 antibody (D7F9A, Cell Signaling Technology) or normal rabbit serum (NRS) diluted in PBS at 1:1000, by using Vectastain ${ }^{\circledR}$ Elite ABC Kit (Vector Laboratories, Burlingame, USA), according to the manufacturer's instructions. Tissues were counterstained with Mayer's hematoxylin and mounted with DPX Mountant (Sigma). Bright-field microscopy images were captured using Zeiss AxioVert-200 M microscope with AxioCam-MRc camera using LD A-Plan $\times 20 / 0.30$ objective (Zeiss GmbH, Oberkochen, Germany).

\section{Statistical analysis}

Two-tailed Student's $t$ test and Mann-Whitney $U$ test were used to compare the levels of continuous variables in the dichotomous class variables according to the variable's distribution. Intravitreal $e \mathrm{~N} / \mathrm{CD} 73$ activity was normally distributed after square root transformation, and Ang-1 and Ang2 normal distribution was achieved after $\ln$ transformation. To study the mean ranks of continuous variables, Kruskal-Wallis test was used for all variables. Non-parametric Spearman's correlation coefficients were computed to investigate the inter-correlations of continuous variables (SAS Institute., Cary, NC, USA). In case of comparative studies, the researcher(s) analyzed the encoded vitreous samples provided by the surgeon in a masked way, without knowing the clinical status of the patients. The statistical significance levels were denoted as $* P<0.05$ and $* * P<0.01$.

\section{Results}

\section{The identification of soluble eN/CD73 and AK1 enzymes in the human vitreous fluid}

This work was undertaken to characterize the pattern of purine homeostasis in unique biological fluids collected from vitrectomized eyes of the patients with various vitreoretinal disorders. Figure 1 schematically outlines the principal design of this study.

We took advantage of radio-TLC for autoradiographic screening of purine-converting pathways. As shown in Fig. 2a, VF from patients with RRD efficiently hydrolysed $\left[{ }^{3} \mathrm{H}\right] \mathrm{AMP}$ into $\left[{ }^{3} \mathrm{H}\right]$ adenosine (lane 2 ), while specific inhibitor of $e \mathrm{~N} / \mathrm{CD} 73 \mathrm{APCP}[31]$ blocked this nucleotidase reaction 


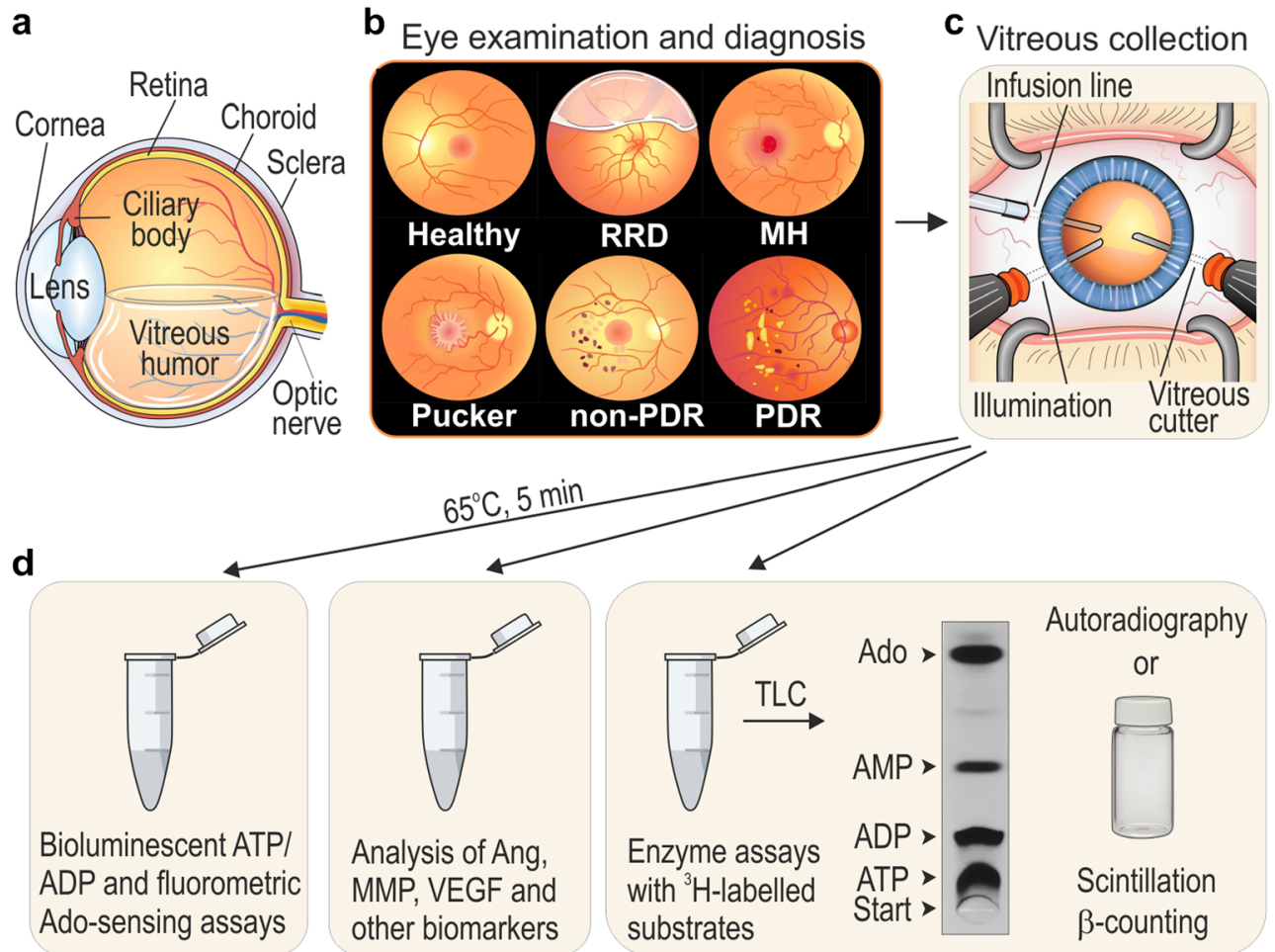

Fig. 1 Study design. a Schematic illustrations of the cross section of the eye and $\mathbf{b}$ the fundus of the eyes from healthy subjects and patients with RRD, MH, pucker, non-PDR, and PDR. Surgical enrolment criteria for diabetic vitrectomy were non-clearing vitreous hemorrhage, traction retinal detachment, or diabetic macular edema with vitreomacular traction. In the eyes with PDR, perfused neovessels were observed on the retina or optic disk during vitrectomy. c Vitreous humors were collected from the patients by manual aspiration into a syringe at the start of the conventional three-port pars plana vitrectomy. d Sample aliquots were subjected to analysis of intravitreal levels of ATP, ADP, adenosine, and other biomarkers, as well as TLC-based enzymatic assays. For purine-sensing assays, VFs were heat inactivated for $5 \mathrm{~min}$ at $65{ }^{\circ} \mathrm{C}$. For pictorial illustration, aliquots of $\left[{ }^{3} \mathrm{H}\right] \mathrm{ATP},\left[{ }^{3} \mathrm{H}\right] \mathrm{ADP}$, $\left[{ }^{3} \mathrm{H}\right] \mathrm{AMP}$, and $\left[{ }^{3} \mathrm{H}\right]$ Ado $(\sim 1 \mu \mathrm{l}$ each $)$ were pooled, separated by TLC, and developed by autoradiography. The arrows indicate the positions of ${ }^{3} \mathrm{H}$-labeled nucleotides and adenosine (Ado) (lane 3). In the presence of $\gamma$-phosphate-donating ATP, part of $\left[{ }^{3} \mathrm{H}\right] \mathrm{AMP}$ was converted into ${ }^{3} \mathrm{H}$-labeled ADP/ATP (lane 4), whereas $\mathrm{AK}$ inhibitor $\mathrm{Ap}_{5} \mathrm{~A}$ prevented this phosphotransfer reaction (lane 5). A substantial band corresponding to $\left[{ }^{3} \mathrm{H}\right]$ AMP can be detected after incubating the sample with $\left[{ }^{3} \mathrm{H}\right] \mathrm{ADP}$ (lane 7). However, the inhibition of $\left[{ }^{3} \mathrm{H}\right] \mathrm{ADP}$ breakdown by $\mathrm{Ap}_{5} \mathrm{~A}$ (lane 8 ), together with the negligible $\left[{ }^{3} \mathrm{H}\right] \mathrm{ATP}$ hydrolyzing capability of VF (lane 11), indicates that intravitreal nucleotide metabolism occurs through AK rather than "true" NTPDase activity. Moreover, the ability of VF to further transphosphorylate $\left[{ }^{3} \mathrm{H}\right] \mathrm{ADP}$ and ATP into $\left[{ }^{3} \mathrm{H}\right] \mathrm{ATP}$ and ADP suggests the existence of yet another nucleotide kinase, NDPK (lane 9).

Consistent with the autoradiographic data, a direct quantitative analysis confirmed the ability of VF to hydrolyse $\left[{ }^{3} \mathrm{H}\right] \mathrm{AMP}$ and also to phosphorylate both $\left[{ }^{3} \mathrm{H}\right] \mathrm{AMP}$ and $\left[{ }^{3} \mathrm{H}\right] \mathrm{ADP}$ in an ATP-dependent manner. The employment of $\left[{ }^{3} \mathrm{H}\right]$ ATP, $\left[{ }^{3} \mathrm{H}\right]$ ADP (in combination with $\mathrm{Ap}_{5} \mathrm{~A}$ ), and $\left[{ }^{3} \mathrm{H}\right]$ adenosine as initial substrates revealed low but clearly detectable ATPase activities in the VF from some (four out of eight) patients and the absence of ADPase and adenosine deaminase in all specimens studied (Fig. 2b). Importantly, removal of potential microparticles or tissue debris by additional centrifugation and filtering the samples did not affect the measured rates of $\left[{ }^{3} \mathrm{H}\right]$ AMP hydrolysis and phosphorylation (Fig. 2c).

To further identify the nature of these activities, VFs were incubated with Protein-A Sepharose beads coupled to different immunoglobulins. CD73-depleted VFs are characterized by markedly diminished $\left[{ }^{3} \mathrm{H}\right]$ AMP-hydrolyzing capability, thus confirming that CD73 accounts for more than $90 \%$ of intravitreal AMPase. Likewise, compared with mocktreated controls, VF depleted of AK1 (but not of another enzyme isoform AK2) were characterized by $\sim 65 \%$ lower rate of ATP-induced $\left[{ }^{3} \mathrm{H}\right]$ AMP phosphorylation (Fig. 2d). The residual $35 \%$ of activity might reflect either insufficient depleting efficacy of anti-AK1 antibody or the co-existence of other AK isoform(s). Collectively, our data identified AK1 as a key soluble enzyme mediating reversible transphosphorylation of two ADP molecules into ATP and AMP and comprising, in conjunction with NDPK, an efficient ATP-regenerating pathway in the human VF. Moreover, soluble $e \mathrm{~N} / \mathrm{CD} 73$ mediates hydrolysis of AMP into adenosine, whereas NTPDase and adenosine deaminase 

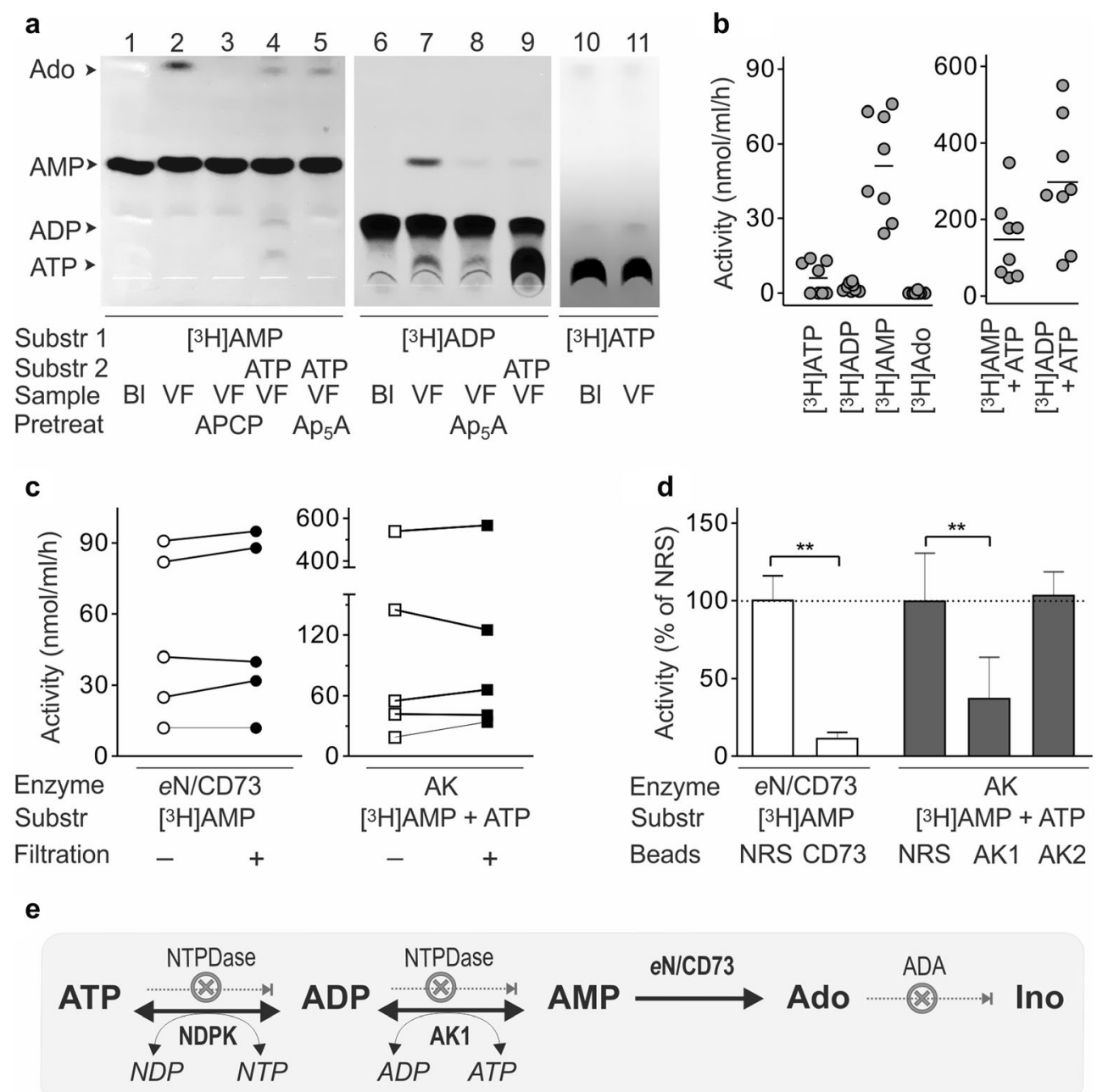

Fig. 2 Characterization of purine homeostasis in the human vitreous fluid. a VF from RRD patients were pre-treated without and with APCP or $\mathrm{Ap}_{5} \mathrm{~A}$ and then incubated with $\left[{ }^{3} \mathrm{H}\right] \mathrm{AMP},\left[{ }^{3} \mathrm{H}\right] \mathrm{ADP},\left[{ }^{3} \mathrm{H}\right] \mathrm{ATP}$, and also with $\left[{ }^{3} \mathrm{H}\right]$ AMP plus ATP, as indicated. Mixture aliquots were separated by TLC and developed by autoradiography. The arrows indicate the positions of nucleotides and adenosine (Ado). The blanks $(B l)$ show the radiochemical purity of tracer substrates in the absence of VF. b Vitreous purine-converting activities were assayed using ${ }^{3} \mathrm{H}-$ labeled and unlabeled nucleotides and adenosine as substrates. Each symbol represents one patient, and the vertical lines indicate the means $(n=8)$. $\mathbf{c}$ The rates of $\left[{ }^{3} \mathrm{H}\right]$ AMP hydrolysis and ATP-mediated $\left[{ }^{3} \mathrm{H}\right]$ AMP phosphorylation were determined in the VF from five RRD patients before (open symbols) and after (closed symbols) centrifugation of the samples and passing the obtained supernatants through $0.22-\mu \mathrm{m}$ filters.

seem not to contribute significantly to the intravitreal purine metabolism (Fig. 2e).

\section{Comparative analysis of intravitreal $\mathrm{AK}$ and $\mathrm{eN} / \mathrm{CD} 73$ activities in diabetic vs. non-diabetic eyes}

We then evaluated the pattern of ocular nucleotide homeostasis at certain pathological conditions, by measuring the activities of $e \mathrm{~N} / \mathrm{CD} 73$ and $\mathrm{AK}$ in the VF from both non-diabetic and diabetic patients. Detailed information on diabetic
Enzymatic activities in $\mathbf{b}$ and $\mathbf{c}$ were expressed as nanomoles of ${ }^{3} \mathrm{H}$ labeled substrate inactivated (left panels) or phosphorylated (right) by milliliter of VF per hour. d VF samples were pre-treated with beads coupled to antibodies against $e \mathrm{~N} / \mathrm{CD} 73, \mathrm{AK} 1$, and $\mathrm{AK} 2$, as well as normal rabbit serum (NRS). The activities of $e \mathrm{~N} / \mathrm{CD} 73$ and adenylate kinase (AK) were quantified from three assays, each performed with $\mathrm{VF}$ pooled from three patients and expressed as the percentage of control activity determined in the NRS-treated samples (mean $\pm \mathrm{SD}$, total $n=9$ ). ${ }^{* *} P<0.01$. e The scheme highlights the exchange activities of adenine nucleotides and adenosine in the human vitreous. Major converting pathways mediated through soluble $e \mathrm{~N} / \mathrm{CD} 73, \mathrm{AK} 1$, and NDPK reactions have been identified and outlined in bold, while NTPDase and adenosine deaminase (ADA) do not seem to contribute significantly to the intravitreal purine homeostasis

mellitus, age, and gender distribution among the patients studied is provided in Table 1. Analysis of the glycemic status confirmed that in comparison with a normal reference range of $4-6 \%$ determined in healthy persons, the levels of glycated HbA1c were significantly elevated in blood of diabetic patients (Table 1).

The ability of VF to hydrolyse $\left[{ }^{3} \mathrm{H}\right] \mathrm{AMP}$ (Fig. 3a, b) and also to mediate its ATP-dependent phosphorylation (Fig. 3c, d) varied substantially among the individuals. No significant differences in intravitreal $e \mathrm{~N} / \mathrm{CD} 73$ activities 

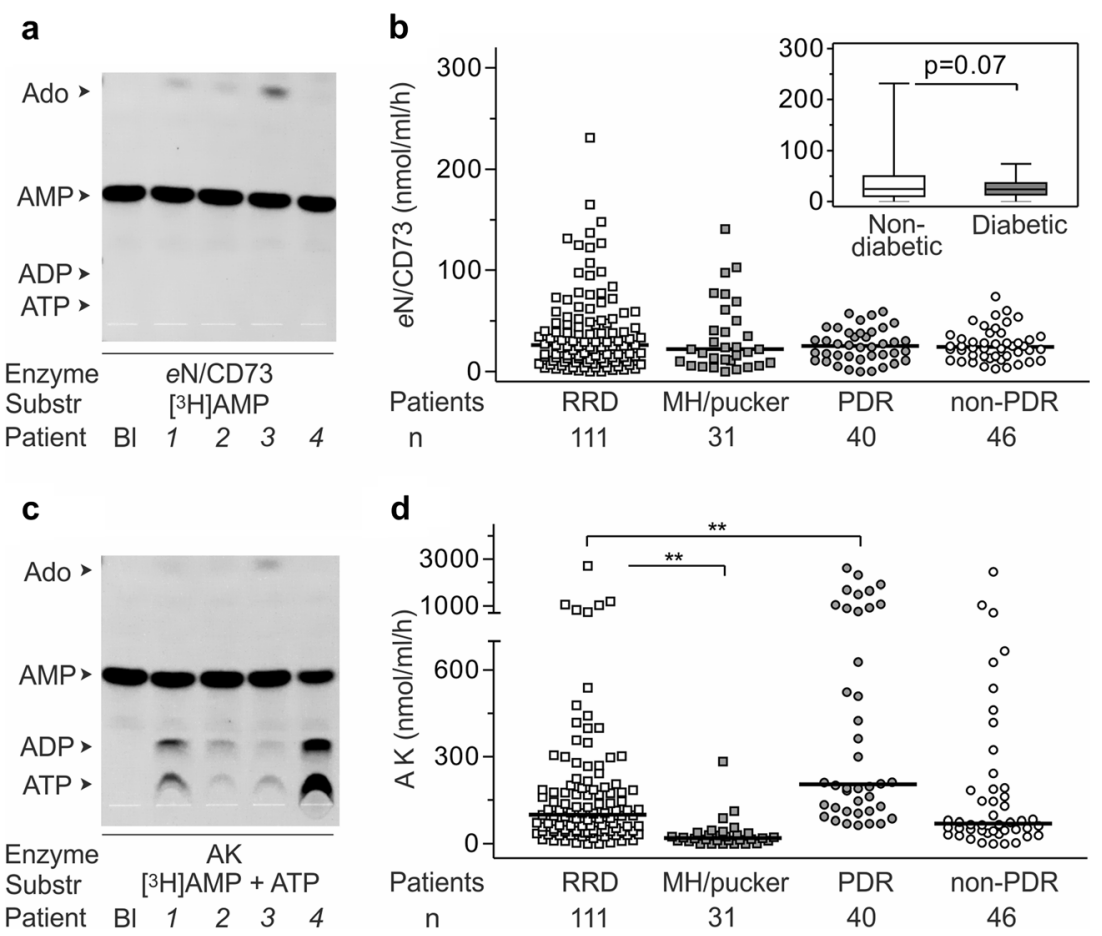

Fig. 3 Intravitreal nucleotide-converting enzymes in non-diabetic and diabetic eyes. Representative autoradiographic images depict the pattern of $\left[{ }^{3} \mathrm{H}\right] \mathrm{AMP}$ metabolism in the VF from three RRD (1-3) and one PDR (4) patients, as determined in the absence (a) and presence (c) of $\gamma$ phosphate-donating ATP. The arrows indicate the positions of nucleotide standards and adenosine $(A d o)$. The blanks $(B l)$ show the radiochemical purity of $\left[{ }^{3} \mathrm{H}\right] \mathrm{AMP}$. Specific $e \mathrm{~N} / \mathrm{CD} 73$ (b) and $\mathrm{AK}(\mathbf{d})$

activities were quantified by scintillation $\beta$-counting in the VF from the indicated groups of patients and presented as scatterplots. Each dot represents an individual patient, and the horizontal line indicates the median. The ordinates show the catalytic activities expressed as nanomoles of $\left[{ }^{3} \mathrm{H}\right]$ AMP hydrolyzed (b) or phosphorylated (d) by milliliter of VF per hour. $* * P<0.01$

were determined among the groups studied; however, there was a clear trend in diminished $\left[{ }^{3} \mathrm{H}\right] \mathrm{AMP}$ hydrolysis in the diabetic eyes (Fig. 3b, inset). On the contrary, VF from diabetic patients were characterized by markedly elevated rates of ATP-mediated $\left[{ }^{3} \mathrm{H}\right]$ AMP phosphorylation, with the most striking up-regulation in AK activity being observed in the cohort of PDR patients. Interestingly, additional subgroup analysis revealed that all eyes operated due to $\mathrm{MH}$ or pucker displayed low or undetectable AK activities (Fig. 3d).

\section{The activity of $\mathrm{AK}$, but not $\mathrm{eN} / \mathrm{CD} 73$, correlates with levels of ATP; ADP; and other angiogenic, profibrotic, and proteolytic factors in the eye}

We have shown earlier that in comparison with non-diabetic controls, VFs from DR patients contain higher concentrations of adenine nucleotides [17], as well as Ang-2, VEGF, and other angiogenic and inflammatory biomarkers [6]. More thorough studies with expanded numbers of patients further demonstrated selective diabetes-related increases in ATP concentrations in the VF, but not in the blood plasma, accompanied by 2-3-fold increase in ATP/ADP ratios in the PDR and also non-PDR eyes (Table 1). Most likely, the revealed increases in intravitreal ATP occur locally in the diabetic eye, without any shifts in nucleotide levels in the systemic circulation.

The non-parametric correlation analysis revealed the existence of positive correlations between intravitreal AK activity and ATP and ADP levels, as well as MMP-9, TGF $\beta 1$, Ang-1, and Ang-2 (but not VEGF and erythropoietin), with the highest Spearman's $r$ coefficients being observed in the diabetic eyes (Fig. 4 and Supplementary Fig. 1). Interestingly, while no significant differences in intravitreal adenosine concentrations were determined among the groups studied [17] (also Table 1), there was a significant inverse correlation between this nucleoside and AK activity in the PDR eyes (Fig. 4c). By contrast, $e \mathrm{~N} / \mathrm{CD} 73$ activity displayed relatively poor or insignificant correlations with intravitreal concentrations of purines and other mitogenic, vasculotropic, profibrotic, and inflammatory biomarkers (Fig. 5 and Supplementary Fig. 2).

\section{Immunohistochemical analysis of $e \mathrm{~N} / \mathrm{CD} 73$ distribution in the human retina}

The innermost retina may serve as one of the major sources of enzymes secreted to the VF. During histological preparation, the retina is known to be frequently detached from the 
Fig. 4 Correlation analysis between $\mathrm{AK}$ activity and various biomarkers in human vitreous. The activity of AK was assayed in VF from non-diabetic and diabetic eyes and further correlated with intravitreal concentrations of ATP (a), ADP (b), adenosine (c), and VEGF (d). Similar analysis was also performed for TGF $\beta 1$, erythropoietin (EPO), MMP-9, Ang-1, and Ang-2 (see Supplementary Fig. 1), and e summarizes the non-parametric Spearman's correlation coefficients (Spearman's $r$ ) computed to investigate the relationship between AK activity and these intravitreal biomarkers. $n d$ not determined due to insufficient number of samples. $* P<0.05$ and $* * P<0.01$ a

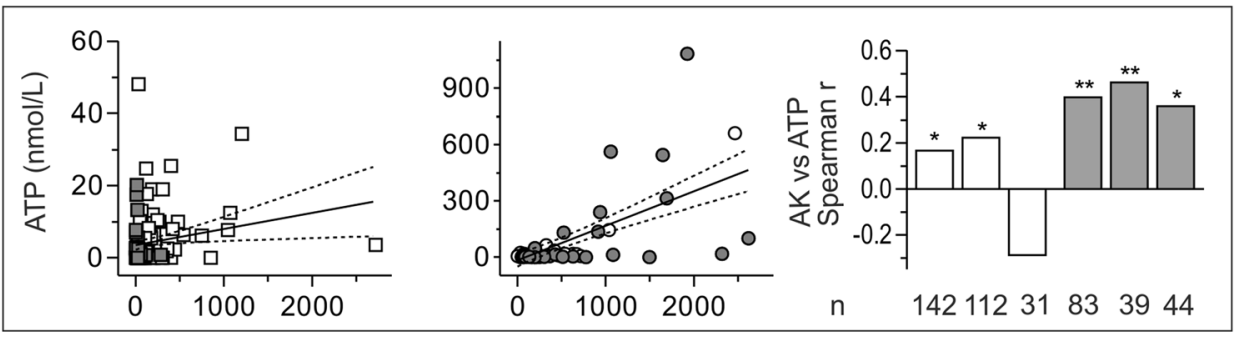

b

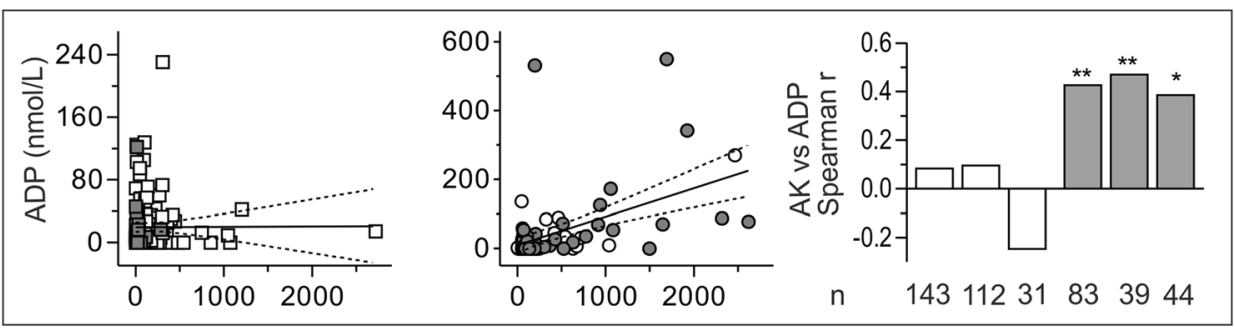

c

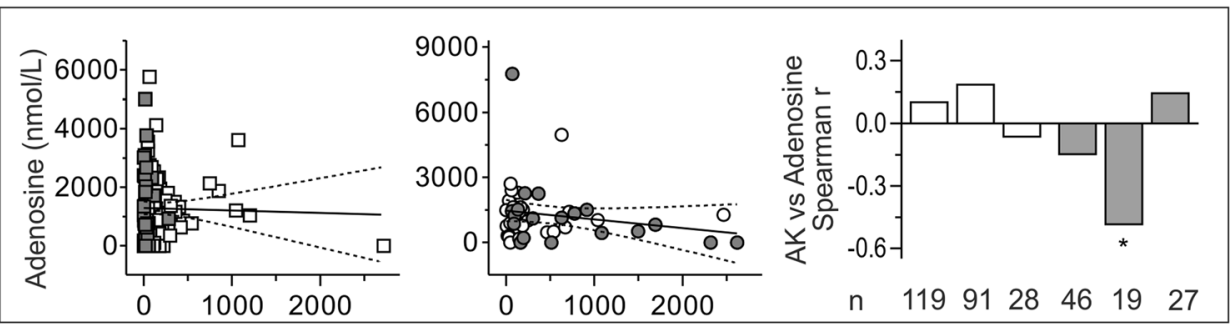

d

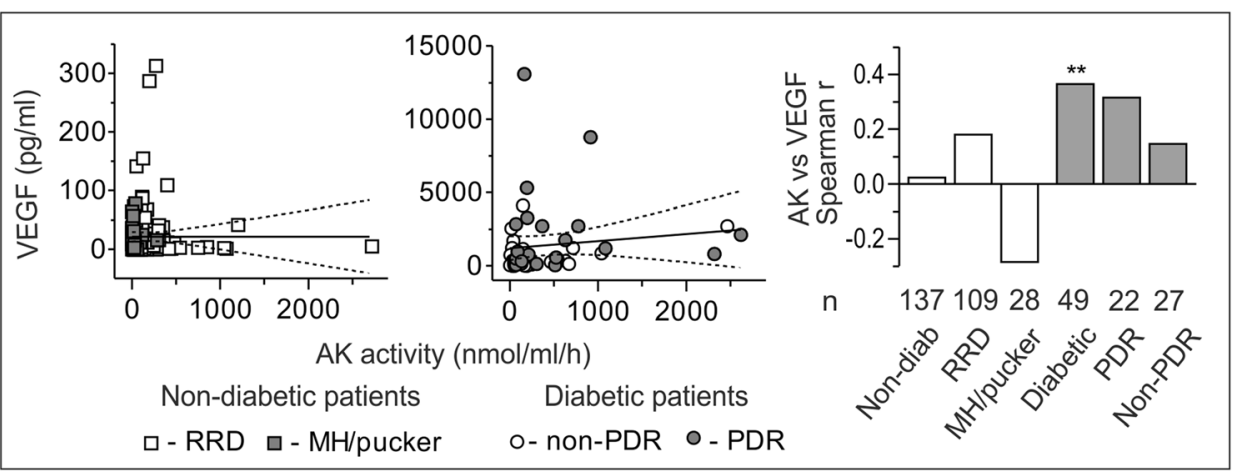

e

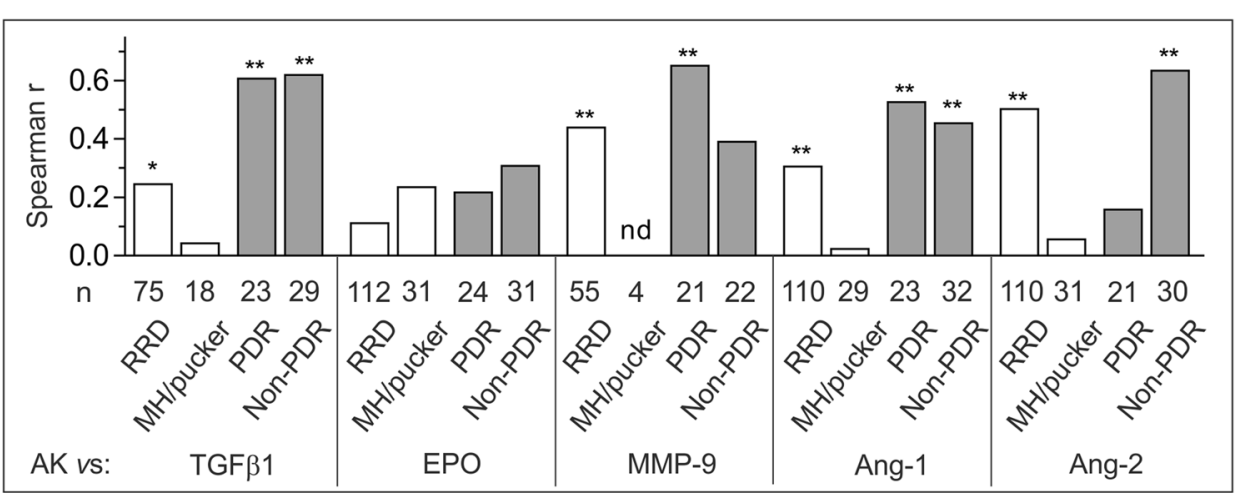

wall of the eye and the plane of cleavage is usually between the photoreceptors and the retinal pigment epithelium. Nevertheless, well-preserved paraffin sections of human retina were available for histochemical staining, and the obtained results demonstrated the abundant expression of $e \mathrm{~N} /$ CD73 in the outer nuclear layer but not in the ganglion cells (Fig. 6).

\section{Discussion}

We have identified soluble enzymes, eN/CD73, AK (mainly comprising of AK1 isoform), and NDPK, in the human VF and further demonstrated that AK activity is selectively up-regulated in the PDR patients, as compared with non-diabetic controls. Constitutive 
Fig. 5 Correlation analysis between $e \mathrm{~N} / \mathrm{CD} 73$ activity and various biomarkers in human vitreous. The activity of $e \mathrm{~N} / \mathrm{CD} 73$ was assayed in VF from nondiabetic and diabetic eyes and further correlated with intravitreal concentrations of ATP (a), ADP (b), adenosine (c), and VEGF (d). Similar analysis was also performed for TGF $\beta 1$, erythropoietin (EPO), MMP-9, Ang-1, and Ang-2 (see Supplementary Fig. 2), and e summarizes the non-parametric Spearman's correlation coefficients (Spearman's $r$ ) computed to investigate the relationship between eN/CD73 and these intravitreal biomarkers. $n d$ not determined due to insufficient number of samples. $* P<0.05$ and $* * P<0.01$ a

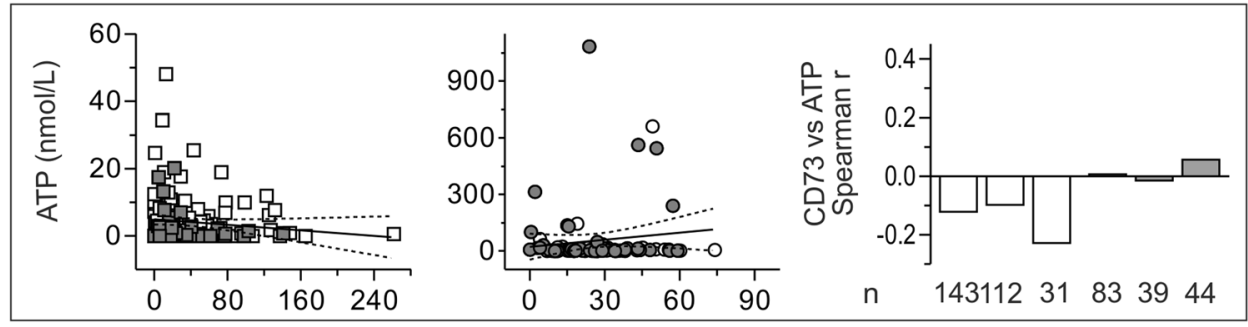

b

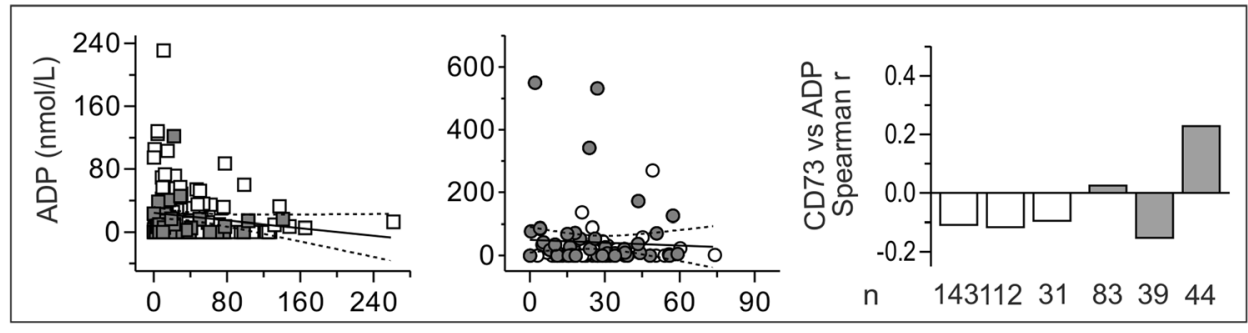

c

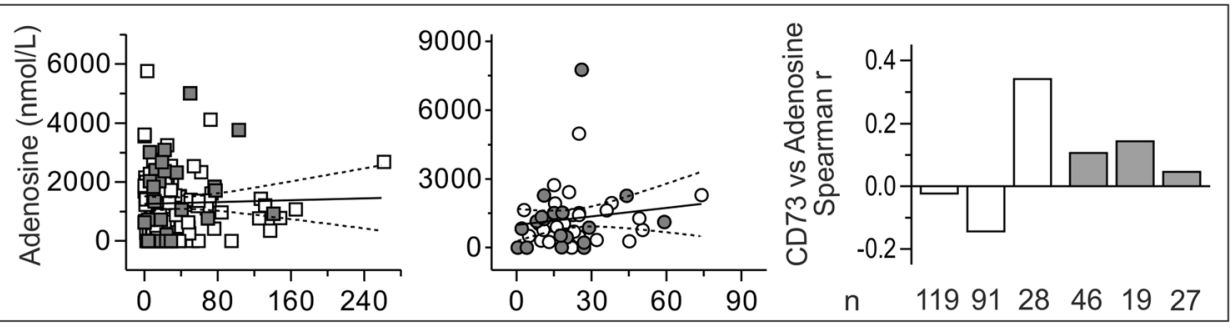

d

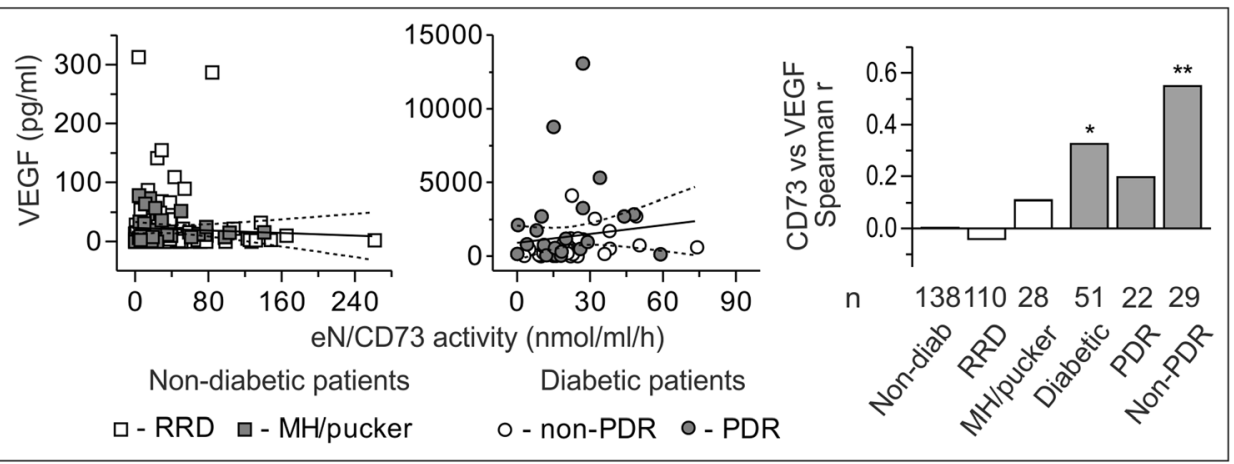

e

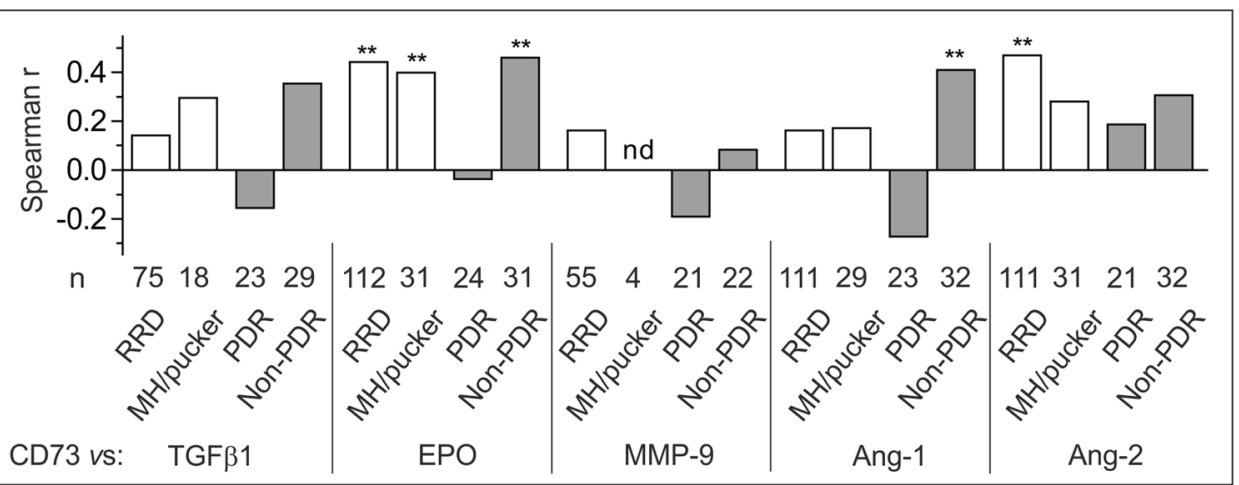

presence of intravitreal nucleotide-converting activities, together with wide expression of purinergic receptors and ecto-enzymes in the retina and other ocular structures, comprises a novel and heretofore unrecognized network coordinately regulating nucleotide homeostasis and signaling in the eye.
The discovery of soluble purinergic activities is not a unique phenomenon. A broad spectrum of enzymes (including $e \mathrm{~N} / \mathrm{CD} 73$ and AK1) circulates in the human and murine bloodstream [29, 32] and can be secreted by vascular endothelial, hematopoietic, epithelial, and tumor cells $[19,33]$ and also by sympathetic nerves [34] in response to the application 


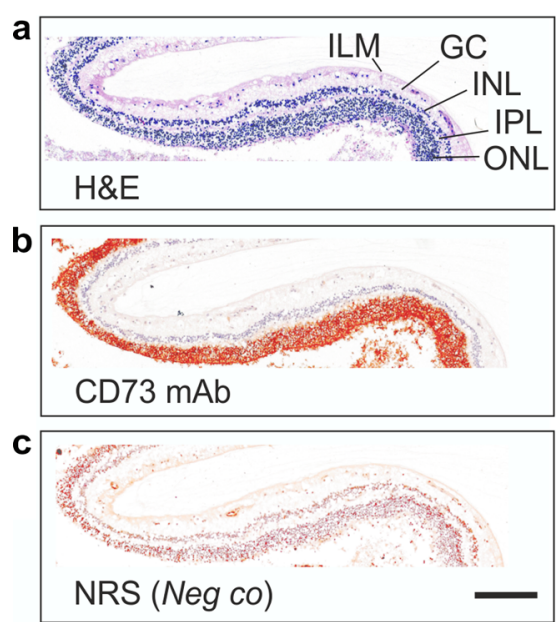

Fig. 6 Distribution of $e \mathrm{~N} / \mathrm{CD} 73$ in human retina. Formalin-fixed, paraffin-embedded human retinal sections were stained with rabbit $\alpha$ CD73 antibody (b) or normal rabbit serum (NRS) as a negative control (c). Tissue sections were also stained with hematoxylin and eosin (H\&E) (a). ILM inner limiting membrane, $G C$ ganglion cell, $I N L$ inner nuclear layer, $I P L$ inner plexiform layer, $O N L$ outer nuclear layer. Scale bar $200 \mu \mathrm{m}$

of shear forces and other mechanical and chemical stimuli. While the origin of intravitreal enzymes remains unknown, it is pertinent to note that $e \mathrm{~N} / \mathrm{CD} 73$ is abundantly expressed in the sensory retina, neuronal cells, corneo-scleral layer, and other eye entities [26, 35] (also current study). The cytosolic enzyme AK1 and its membrane-associated isoform $A K 1 \beta$ are also present in high-energy-demanding tissues, including the brain [19, 36], neuronal cells [37], and outer segments of retina [38]. It may be speculated that certain portions of (ecto)enzymes can be released into the vitreous cavity upon light-evoked neuronal stimulations; dark-light transitions; and during mechanical perturbations caused by incessant eye movements, blinking, and variations in the vascular tone and intraocular pressure.

High concentrations of ATP are known to accelerate apoptosis of photoreceptor cells via ligation of ATP-specific $\mathrm{P} 2 \mathrm{X} 7$ receptors $[16,39]$ and in addition, mediate neurodegeneration, gliosis, neovascularization, inflammation, and vascular leakage $[12,25]$. In felines and rodents, intravitreal administration of ATP induced photoreceptor degeneration, retinal neural remodeling, and Müller cell gliosis, with most of these pathological changes continuing out to 12 weeks postinjection [40]. The identification of intravitreal AK adds another level of complexity to our understanding of ATPmediated retinal dysfunction and degeneration. Marked upregulation of soluble AK in the PDR eyes with advanced retinal hemorrhage may indicate on massive leakage of AK, along with ATP and other transmitters, by injured neurons, glial cells, or extravasated blood cells in the course of retinal degeneration and blood clotting. In the absence of soluble NTPDases, AK and NDPK comprise the predominant nucleotide-converting pathway in the VF by mediating continuous resynthesis of the released ATP through sequential phosphotransfer reactions. Interestingly, in a Drosophila model of human tauopathy, the retinal expression of human AK1 severely exacerbated a rough eye phenotype and contributed to an abnormal tau-mediated neurodegeneration in transgenic flies [37]. Vitreous and humoral fluids and tears also contain diadenosine polyphosphates $\left(\mathrm{Ap}_{\mathrm{n}} \mathrm{A} ; n=2-6\right)$, a family of dinucleotides with diverse physiological properties in the eye [13] and other tissues [41]. $A p_{n} A$ are thought to exert their actions either directly by means of $\mathrm{P} 2 \mathrm{X}$ and $\mathrm{P} 2 \mathrm{Y}$ receptors or via ecto-enzymatic conversion into ATP and other biologically active metabolites [13, 19, 41]. Potent inhibition of both membrane-bound [31] and soluble [32] (present study) AK by $\mathrm{Ap}_{5} \mathrm{~A}$ may provide an alternative explanation of the therapeutic effects of this bisubstrate analog, via prevention of excessive AK-mediated formation of ATP in the eye.

Data on the presence of $e \mathrm{~N} / \mathrm{CD} 73$ in the VF and specific enzyme distribution along the sensory retina further extend our knowledge on the purinergic mechanisms in the human eye. Taking into account the involvement of adenosinergic signaling in modulation of the light responses of photoreceptors, retinal hyperemia, and protection of neurons from hyperexcitation and glutamate toxicity $[8,11,14]$, it may be hypothesized that $e \mathrm{~N} / \mathrm{CD} 73$-mediated generation of adenosine represents an important constituent of purinergic signaling machinery in the healthy retina. Recent identification of $e N / C D 73$ as a novel biomarker of the early stages of the photoreceptor lineage and the increased integration of transplanted CD73enriched photoreceptor precursors in the adult mouse retina $[35,42,43]$ also provide sufficient background for manipulation of ocular adenosine homeostasis as a promising strategy for stem cell-derived replacement therapy. However, prolonged increases in adenosine concentrations may be injurious to the retina, mainly due to enhanced formation of superoxide radicals secondary to adenosine metabolism $[8,14]$. Surprisingly, despite the abundant $e \mathrm{~N} / \mathrm{CD} 73$ expression on the rod-and-cone-containing photoreceptor cells (see Fig. 6b), endogenous adenosine and its receptors were shown to be compartmentalized in the ganglion cells and inner plexiform layer [8]. This apparent discrepancy presumably reflects high turnover rate of (extra)cellular purines in the outer retinal segments, with only transient formation of adenosine as an intermediate metabolite of the nucleotide-inactivating chain.

Assessment of the physiological relevance of intravitreal enzymes is another important issue. Given that the VF represents the largest structure within the eye occupying about $80 \%$ of the ocular volume [44], soluble enzymes could comprise an important auxiliary effector system for tuned regulation of nucleotide concentrations in the eye. For instance, large surface-to-volume ratio of the retina may facilitate diffusion of soluble $e \mathrm{~N} / \mathrm{CD} 73$ and its metabolite adenosine from the vitreous core to the vitreoretinal interface, thereby contributing to the known phenomenon of relative tolerance and functional 
recovery of the inner retina even after extended periods of acute ischemia and hypoxia [1]. The balance between membrane-associated and soluble enzymes can be further shifted under certain pathogenic states, including inflammation, hypoxia, oxidative stress, vascular lesion, and age- or diabetes-related liquefaction of the vitreous body. In fact, since the retina is one of the most metabolically active and oxygen-sensitive tissues in the body, it is continuously at risk for developing tissue ischemia and hypoxia, especially during DR, age-related macular degeneration, and other pathological states $[1,4]$. While the expression levels of ecto-nucleotidases in the retina of diabetic patients still remain to be elucidated, in the cardiovascular system, endothelial ecto-nucleotidase activities were shown to be diminished under conditions of myocardial infarction and ischemia-reperfusion injury [20, 45], atherogenesis [46], chronic hypoxia [47], hypothermia [48], transplantation, and stroke [49], accompanied by elevated levels of intravascular ATP and ADP and profound shifts in vascular permeability, blood flow, and local pro-coagulant responses. One of the promising strategies to offset the reduced nucleotide-scavenging effectiveness of injured vascular endothelium includes the administration of recombinant human NTPDase1/CD39 [48, 49] or soluble NTPDase3 (APT102) [45] for anti-platelet, anti-inflammatory, and cardioprotection therapies.

On the other hand, concurrently elevated soluble AK activity and ATP concentration in the PDR eyes (current study), together with feed-forward inhibition of $e \mathrm{~N} / \mathrm{CD} 73$-mediated hydrolysis of AMP into adenosine by precursor nucleotides ATP and ADP [31], might serve as unfavorable pathogenic factors maintaining chronically elevated ATP levels and triggering spatial propagation of inflammatory responses into the surrounding retina far distant from the site of focal detachment. The contribution of AK-mediated ATP formation to the pathogenesis of DR is further ascertained by the existence of positive correlations between the AK activity and other angiogenic (Ang-1), profibrotic (TGF $\beta 1$ ), and proteolytic (MMP-9) factors, with the highest Spearman's $r$ coefficients being observed in the PDR eyes (see Fig. 4). Interestingly, previous proteomic analysis of VF from PDR and non-PDR patients has also shown that the quantitative proteome differs between these two disease states, with a number of immunomodulatory, pro-apoptotic, and growth factor molecules being up-regulated only in the PDR eyes [7]. While another intravitreal enzyme $e \mathrm{~N} / \mathrm{CD} 73$ displayed relatively poor correlations with concentrations of purines and other biomarkers, it is worth mentioning the existence of positive interrelations between $e \mathrm{~N} / \mathrm{CD} 73$ activity and EPO levels in non-diabetic and non-PDR, but not in PDR, eyes (see Fig. 5). EPO, a secreted glycoprotein of the type I cytokine family, plays a central role in VEGF-independent protection of retinal ganglion cells and photoreceptors via pleiotropic mechanisms $[1,5]$. Since both EPO [1] and $e \mathrm{~N} / \mathrm{CD} 73$ [23] expressions can be regulated by hypoxia-inducible transcription factor- $1 \alpha$ $(\mathrm{HIF} 1 \alpha)$, further studies are required to elucidate how these molecules regulate tissue oxygenation and promote survival and recovery of photoreceptor cells in certain compensatory or synergistic manners.

In summary, the identification of soluble intravitreal enzymes provides novel insights into the mechanisms that influence purinergic signaling pathways in the human eye. Data on concurrently elevated AK activities and ATP levels in the VF from PDR patients suggest selective diabetes-related shifts in ocular purine homeostasis from generation of the antiinflammatory adenosine toward a pro-inflammatory ATPregenerating phenotype. It is conceivable but remains to be experimentally proven that directional restoration of the adenosine-generating capacity in the diabetic eye via increasing $e \mathrm{~N} / \mathrm{CD} 73$ expression on photoreceptor cells or intraocular application of soluble nucleotidases, in combination with blocking of ATP re-synthesis by using selective AK inhibitors, might open up new possibilities in the development of innovative enzyme-targeted therapeutic approaches for prevention and treatment of DR.

Acknowledgments This work was supported by grants from the Academy of Finland, the Sigrid Juselius Foundation, the European Community's Seventh Framework Program (FP7/2007-2013; grant agreement no. 602200) (SJ and GGY), the Finnish Eye Foundation, the Eye and Tissue Bank Foundation, the Mary and Georg C. Ehrnrooth Foundation, the Nissi Foundation, the Friends of the Blind, and $\mathrm{HUCH}$ Clinical Research Grants (TYH2016230 after TYH1325) (SL). We are grateful to Professors Be Wieringa and Jean Sevigny for providing the antibodies. We thank Professor Pier Enrico Gallenga and Drs. Giuseppe Lattanzio, Markku Kallajoki, and Maria Gardber for their expert help in examining the histological samples. We also thank Sari Mäki and Teija Kanasuo for their technical assistance, Seija Rusanen for drawing the schematic eye images, and Ruth Fair-Mäkelä for the revision of the text.

\section{Compliance with ethical standards}

Conflict of interest The authors declare that they have no conflict of interest.

\section{References}

1. Caprara C, Grimm C (2012) From oxygen to erythropoietin: relevance of hypoxia for retinal development, health and disease. Prog Retin Eye Res 31:89-119

2. Loukovaara S, Gucciardo E, Repo P, Vihinen H, Lohi J, Jokitalo E, Salven P, Lehti K (2015) Indications of lymphatic endothelial differentiation and endothelial progenitor cell activation in the pathology of proliferative diabetic retinopathy. Acta Ophthalmol 93:512523

3. Simo R, Hernandez C (2015) Novel approaches for treating diabetic retinopathy based on recent pathogenic evidence. Prog Retin Eye Res 48:160-180 
4. Stitt AW, Curtis TM, Chen M, Medina RJ, McKay GJ, Jenkins A, Gardiner TA, Lyons TJ, Hammes HP, Simo R, et al. (2016) The progress in understanding and treatment of diabetic retinopathy. Prog Retin Eye Res 51:156-186

5. Cheung N, Mitchell P, Wong TY (2010) Diabetic retinopathy. Lancet 376:124-136

6. Loukovaara S, Robciuc A, Holopainen JM, Lehti K, Pessi T, Liinamaa J, Kukkonen KT, Jauhiainen M, Koli K, Keski-Oja J, et al. (2013) Ang-2 upregulation correlates with increased levels of MMP-9, VEGF, EPO and TGFbeta1 in diabetic eyes undergoing vitrectomy. Acta Ophthalmol 91:531-539

7. Loukovaara S, Nurkkala H, Tamene F, Gucciardo E, Liu X, Repo P, Lehti K, Varjosalo M (2015) Quantitative proteomics analysis of vitreous humor from diabetic retinopathy patients. J Proteome Res 14:5131-5143

8. Ghiardi GJ, Gidday JM, Roth S (1999) The purine nucleoside adenosine in retinal ischemia-reperfusion injury. Vis Res 39:2519-2535

9. Crooke A, Guzman-Aranguez A, Peral A, Abdurrahman MK, Pintor J (2008) Nucleotides in ocular secretions: their role in ocular physiology. Pharmacol Ther 119:55-73

10. Guzman-Aranguez A, Santano C, Martin-Gil A, Fonseca B, Pintor J (2013) Nucleotides in the eye: focus on functional aspects and therapeutic perspectives. J Pharmacol Exp Ther 345:331-341

11. Sanderson J, Dartt DA, Trinkaus-Randall V, Pintor J, Civan MM, Delamere NA, Fletcher EL, Salt TE, Grosche A, Mitchell CH (2014) Purines in the eye: recent evidence for the physiological and pathological role of purines in the RPE, retinal neurons, astrocytes, Muller cells, lens, trabecular meshwork, cornea and lacrimal gland. Exp Eye Res 127:270-279

12. Reichenbach A, Bringmann A (2016) Purinergic signaling in retinal degeneration and regeneration. Neuropharmacology 104:194-211

13. Guzman-Aranguez A, Crooke A, Peral A, Hoyle CH, Pintor J (2007) Dinucleoside polyphosphates in the eye: from physiology to therapeutics. Prog Retin Eye Res 26:674-687

14. Zhong Y, Yang Z, Huang WC, Luo X (2013) Adenosine, adenosine receptors and glaucoma: an updated overview. Biochim Biophys Acta 1830:2882-2890

15. Lu W, Hu H, Sevigny J, Gabelt BT, Kaufman PL, Johnson EC, Morrison JC, Zode GS, Sheffield VC, Zhang X, et al. (2015) Rat, mouse, and primate models of chronic glaucoma show sustained elevation of extracellular ATP and altered purinergic signaling in the posterior eye. Invest Ophthalmol Vis Sci 56:3075-3083

16. Notomi S, Hisatomi T, Murakami Y, Terasaki H, Sonoda S, Asato R, Takeda A, Ikeda Y, Enaida H, Sakamoto T, et al. (2013) Dynamic increase in extracellular ATP accelerates photoreceptor cell apoptosis via ligation of $\mathrm{P} 2 \mathrm{RX} 7$ in subretinal hemorrhage. PLoS One 8:e53338

17. Loukovaara S, Sahanne S, Jalkanen S, Yegutkin GG (2015) Increased intravitreal adenosine 5'-triphosphate, adenosine 5'-diphosphate and adenosine $5^{\prime}$-monophosphate levels in patients with proliferative diabetic retinopathy. Acta Ophthalmol 93:67-73

18. Burnstock G, Novak I (2013) Purinergic signalling and diabetes. Purinergic Signal 9:307-324

19. Yegutkin GG (2008) Nucleotide- and nucleoside-converting ectoenzymes: important modulators of purinergic signalling cascade. Biochim Biophys Acta 1783:673-694

20. Eltzschig HK, Sitkovsky MV, Robson SC (2012) Purinergic signaling during inflammation. N Engl J Med 367:2322-2333

21. Zimmermann H, Zebisch M, Strater N (2012) Cellular function and molecular structure of ecto-nucleotidases. Purinergic Signal 8: 437-502

22. Yegutkin GG (2014) Enzymes involved in metabolism of extracellular nucleotides and nucleosides: functional implications and measurement of activities. Crit Rev Biochem Mol Biol 49:473-497
23. Eltzschig HK, Bratton DL, Colgan SP (2014) Targeting hypoxia signalling for the treatment of ischaemic and inflammatory diseases. Nat Rev Drug Discov 13:852-869

24. Idzko M, Ferrari D, Riegel AK, Eltzschig HK (2014) Extracellular nucleotide and nucleoside signaling in vascular and blood disease. Blood 124:1029-1037

25. Newman EA (2015) Glial cell regulation of neuronal activity and blood flow in the retina by release of gliotransmitters. Philos Trans R Soc Lond Ser B Biol Sci 370

26. Iandiev I, Wurm A, Pannicke T, Wiedemann P, Reichenbach A, Robson SC, Zimmermann H, Bringmann A (2007) Ectonucleotidases in Muller glial cells of the rodent retina: involvement in inhibition of osmotic cell swelling. Purinergic Signal 3: 423-433

27. Lu W, Reigada D, Sevigny J, Mitchell CH (2007) Stimulation of the P2Y1 receptor up-regulates nucleoside-triphosphate diphosphohydrolase-1 in human retinal pigment epithelial cells. J Pharmacol Exp Ther 323:157-164

28. Li A, Leung CT, Peterson-Yantorno K, Stamer WD, Civan MM (2011) Cytoskeletal dependence of adenosine triphosphate release by human trabecular meshwork cells. Invest Ophthalmol Vis Sci 52:7996-8005

29. Yegutkin GG, Samburski SS, Jalkanen S (2003) Soluble purineconverting enzymes circulate in human blood and regulate extracellular ATP level via counteracting pyrophosphatase and phosphotransfer reactions. FASEB J 17:1328-1330

30. Helenius M, Jalkanen S, Yegutkin GG (2012) Enzyme-coupled assays for simultaneous detection of nanomolar ATP, ADP, AMP, adenosine, inosine and pyrophosphate concentrations in extracellular fluids. Biochim Biophys Acta 1823:1967-1975

31. Yegutkin GG, Henttinen T, Jalkanen S (2001) Extracellular ATP formation on vascular endothelial cells is mediated by ectonucleotide kinase activities via phosphotransfer reactions. FASEB J 15:251-260

32. Yegutkin GG, Wieringa B, Robson SC, Jalkanen S (2012) Metabolism of circulating ADP in the bloodstream is mediated via integrated actions of soluble adenylate kinase-1 and NTPDase1/CD39 activities. FASEB J 26:3875-3883

33. Donaldson SH, Picher M, Boucher RC (2002) Secreted and cellassociated adenylate kinase and nucleoside diphosphokinase contribute to extracellular nucleotide metabolism on human airway surfaces. Am J Respir Cell Mol Biol 26:209-215

34. Westfall DP, Todorov LD, Mihaylova-Todorova ST (2002) ATP as a cotransmitter in sympathetic nerves and its inactivation by releasable enzymes. J Pharmacol Exp Ther 303:439-444

35. Eberle D, Schubert S, Postel K, Corbeil D, Ader M (2011) Increased integration of transplanted CD73-positive photoreceptor precursors into adult mouse retina. Invest Ophthalmol Vis Sci 52: 6462-6471

36. Janssen E, Kuiper J, Hodgson D, Zingman LV, Alekseev AE, Terzic A, Wieringa B (2004) Two structurally distinct and spatially compartmentalized adenylate kinases are expressed from the AK1 gene in mouse brain. Mol Cell Biochem:256-257

37. Park H, Kam TI, Kim Y, Choi H, Gwon Y, Kim C, Koh JY, Jung YK (2012) Neuropathogenic role of adenylate kinase-1 in Abetamediated tau phosphorylation via AMPK and GSK3beta. Hum Mol Genet 21:2725-2737

38. Notari L, Morelli A, Pepe IM (2003) Studies on adenylate kinase isoform bound to disk membranes of the rod outer segment of bovine retina. Photochem Photobiol Sci 2: 1299-1302

39. Notomi S, Hisatomi T, Kanemaru T, Takeda A, Ikeda Y, Enaida H, Kroemer G, Ishibashi T (2011) Critical involvement of extracellular ATP acting on P2RX7 purinergic receptors in photoreceptor cell death. Am J Pathol 179:2798-2809 
40. Aplin FP, Vessey KA, Luu CD, Guymer RH, Shepherd RK, Fletcher EL (2016) Retinal changes in an ATP-induced model of retinal degeneration. Front Neuroanat 10:46

41. Flores NA, Stavrou BM, Sheridan DJ (1999) The effects of diadenosine polyphosphates on the cardiovascular system. Cardiovasc Res 42:15-26

42. Koso H, Minami C, Tabata Y, Inoue M, Sasaki E, Satoh S, Watanabe S (2009) CD73, a novel cell surface antigen that characterizes retinal photoreceptor precursor cells. Invest Ophthalmol Vis Sci 50:5411-5418

43. Lakowski J, Gonzalez-Cordero A, West EL, Han YT, Welby E, Naeem A, Blackford SJ, Bainbridge JW, Pearson RA, Ali RR, et al. (2015) Transplantation of photoreceptor precursors isolated via a cell surface biomarker panel from embryonic stem cellderived self-forming retina. Stem Cells 33:2469-2482

44. de Smet MD, Gad Elkareem AM, Zwinderman AH (2013) The vitreous, the retinal interface in ocular health and disease. Ophthalmologica 230:165-178

45. Moeckel D, Jeong SS, Sun X, Broekman MJ, Nguyen A, Drosopoulos JH, Marcus AJ, Robson SC, Chen R, Abendschein D (2014) Optimizing human apyrase to treat arterial thrombosis and limit reperfusion injury without increasing bleeding risk. Sci Transl Med 6:248ra105

46. Mercier N, Kiviniemi TO, Saraste A, Miiluniemi M, Silvola J, Jalkanen S, Yegutkin GG (2012) Impaired ATP-induced coronary blood flow and diminished aortic NTPDase activity precede lesion formation in apolipoprotein E-deficient mice. Am J Pathol 180: 419-428

47. Yegutkin GG, Helenius M, Kaczmarek E, Burns N, Jalkanen S, Stenmark K, Gerasimovskaya EV (2011) Chronic hypoxia impairs extracellular nucleotide metabolism and barrier function in pulmonary artery vasa vasorum endothelial cells. Angiogenesis 14: 503-513

48. Straub A, Krajewski S, Hohmann JD, Westein E, Jia F, Bassler N, Selan C, Kurz J, Wendel HP, Dezfouli S, et al. (2011) Evidence of platelet activation at medically used hypothermia and mechanistic data indicating ADP as a key mediator and therapeutic target. Arterioscler Thromb Vasc Biol 31:1607-1616

49. Robson SC, Wu Y, Sun X, Knosalla C, Dwyer K, Enjyoji K (2005) Ectonucleotidases of CD39 family modulate vascular inflammation and thrombosis in transplantation. Semin Thromb Hemost 31: $217-233$ 